\title{
Incidence of multiple Herpesvirus infection in HIV seropositive patients, a big concern for Eastern Indian scenario
}

\author{
Nilanjan Chakraborty*1, Sohinee Bhattacharyya', Chandrav De1, Anirban Mukherjee1, Dwipayan Bhattacharya2, \\ Shantanu Santra ${ }^{3}$, Rathindra N Sarkar³, Dipanjan Banerjee4, Shubhasish K Guha5, Utpal K Datta³ and \\ Sekhar Chakrabarti ${ }^{1}$
}

\begin{abstract}
Background: Human immunodeficiency virus (HIV) infection is associated with an increased risk for human herpes viruses (HHVs) and their related diseases and they frequently cause disease deterioration and therapeutic failures. Methods for limiting the transmission of HHVs require a better understanding of the incidence and infectivity of oral HHVs in HIV-infected patients. This study was designed to determine the seroprevalence of human herpes viruses (CMV, HSV 2, EBV-1, VZV) antibodies and to evaluate their association with age, sex as well as other demographic and behavioral factors.

Results: A study of 200 HIV positive patients from Eastern India attending the Calcutta Medical College Hospital, Kolkata, West Bengal, Apex Clinic, Calcutta Medical College Hospital and ART Center, School of Tropical Medicine, Kolkata, West Bengal was done. Serum samples were screened for antibodies to the respective viruses using the indirect ELISA in triplicates.

CytoMegalo virus (CMV), Herpes Simplex virus type 2 (HSV-2), Varicella Zostervirus (VZV), and Epstein Barr virus (EBV-1) were detected in $49 \%, 47 \%, 32.5 \%$, and $26 \%$ respectively.

Conclusion: This study has contributed baseline data and provided insights in viral OI and HIV co-infection in Eastern India. This would undoubtedly serve as a basis for further studies on this topic.
\end{abstract}

\section{Background}

The HIV/AIDS is a global epidemic and approximately 40 million people are living with HIV/AIDS worldwide [1]. About $95 \%$ of all HIV/AIDS infected people are living in developing countries. It is estimated that India is currently harboring about 5.134 million HIV infected cases and comprises of $65 \%$ cases of Southeast Asia. The HIV/ AIDS pandemic in India has extended beyond the common classification of high-risk groups and now is common among the general population [2,3]. The nation is indeed at the threshold of an exponential growth of this epidemic. Opportunistic Infections (OIs) have been recognized as common complications of HIV infection due

* Correspondence: nilanjanchakraborty@ymail.com

1 Virology Department, ICMR Virus Unit, ID \& BG Hospital, GB4, 57 Dr. SC Banerjee Road Beliaghata, Kolkata-700 010, India

Full list of author information is available at the end of the article to immune deficiency. OI is the main reason behind hospitalization and substantial morbidity in HIV infected patients [4]. It necessitates toxic and expensive therapies and reduces the expected life span of such patients. Virtually all HIV-related mortality is preceded by opportunistic infection [5]. OIs encompass a wide variety of microorganisms that produce fulminant infections in immunocompromised HIV seropositive patients. Viral pathogens causing OI evoke a spectrum of illness ranging from asymptomatic to fulminant diseases in HIVinfected individuals. Since the onset of the acquired immunodeficiency syndrome (AIDS) epidemic in 1980; human herpes viruses have resulted in many of the secondary manifestations of human immunodeficiency virus (HIV) infection such as Painful rash due to Painful rash caused by herpes zoster [6,7]. Almost 45 million people worldwide have been infected with HIV, and prior to 
highly active antiretroviral therapy (HAART), more than $75 \%$ of all HIV-infected individuals developed HHVrelated symptoms. The advent of HAART has decreased the incidence of opportunistic HHV diseases and improved the survival capacity of those who received the therapy. Whether HAART has altered the rate of HHV reemergence from latency or the ability of HHVs to produce clinical manifestations is not established [8]. Clearly, HHV-related malignancies remain a significant problem for the HIV infected patients [9,10]. Cytomegalovirus (CMV), Herpes Simplex virus 1 \& 2 (HSV-1 \& 2), Vericella Zoster virus (VZV), Epstein Barr virus (EBV are the common herpesviruses in Indian subcontinent responsible for viral OIs in HIV positive populations [11]. These herpes viruses are usually acquired in childhood or young adulthood, establish a state of asymptomatic latency, and may eventually reactivate to give clinical disease later in life or following an HIV induced decline in cell-mediated immune control. Herpes simplex virus type 1 (HSV1) and type 2 (HSV2) cause primary and recurrent oral, genital and rectal ulceration and occasionally disseminated visceral and CNS disease [12]. In HIV infected individuals, re-activation of VZV causes prolonged and severe manifestation of herpes zoster [7]. Retinitis is most frequent clinical manifestation of CMV though other manifestations like gastrointestinal disease, encephalitis and pneumonia may occur.

In India, especially in the eastern part (including West Bengal), limited information is available on opportunistic infections among HIV seropositive individuals. The relative frequencies of specific opportunistic diseases may vary in different countries and even in different areas within the same country [[13-15], and [16]]. Early diagnosis of opportunistic infections and prompt treatment definitely contribute to increased life expectancy among infected patients delaying the progression to AIDS [17]. In India, quite often the diagnosis of OI is made only on clinical signs and symptoms or when illness is quite advanced, and by then it may be polymicrobial in nature $[18,19]$. Determining the spectrum of OIs and the changing pattern over the years, in a given region requires adequate surveillance and good diagnostic services that are not available in many parts of the country [20]. There is paucity of reports about nature of etiological agents causing various clinical manifestations in HIV disease in India $[21,22]$. Hence, integrated investigative procedures are vital, especially in early stages of HIV infection. The clinical manifestations of HIV infection in India (like other developing countries) are diverse. Spectrum of OIs with which most of the patients present in the clinics, reflects a wide variety of other endemic diseases prevalent within each region.

Thus, the importance of viruses in engendering many of the secondary opportunistic illnesses (and several of the tumors) of AIDS warrants a survey of their disease manifestations and clinical management. Our objective in this study therefore was to determine the prevalence of antibodies to opportunistic viral antigens in HIV infected Indian population. We focused primarily on the four most prevalent viruses of the herpesviridae family found in Eastern Indian population [22]. This study is aimed at providing baseline data on the prevalence of various viral OIs as part of the preliminary investigation on the dynamics of viral opportunistic infections in immunocompromised population of India. The purposes of this study were to determine the frequency of the major viral opportunistic infections in HIV seropositive patients/ AIDS patients from Eastern India and to determine the risk factors associated with OI at the time of diagnosis among these patients in order to promote a greater awareness and management of this modern day "plague" and its complications.

\section{Materials and methods Study site and patient recruitment}

In our study, we reviewed 200 HIV/AIDS patients, admitted between January 2006 to November 2008 at Calcutta Medical College Hospital, Kolkata, West Bengal, Apex Clinic, Calcutta Medical College Hospital- a referral center for patients of HIV infection or AIDS, and ART Center, School of Tropical Medicine, for the detection of viral opportunistic infections. Their HIV status was confirmed by three ERS(Enzyme Linked Immunosorbent Assay [ELISA], Rapid, Simple), an ELISA(HIV ELISA, Rapid test)and Western Blot as recommended by the National Aids Control Organization (NACO), Ministry of Health and Family Welfare, Government of India. The admitted patients were referred to us because they presented symptoms related to HIV infection or symptoms of unknown origin such as prolonged fever. The study group comprised of $140(70 \%)$ males and $60(30 \%)$ females, with mean ages of $36 \pm 16$ and $35 \pm 12$ years respectively. The patients included in the study were from different states of Eastern India. Our observations included only periods of hospitalization; we did not investigate patients' records after their discharge from the hospital. There were 26 males and 5 females in the patient group.

\section{Investigation of risk factors}

Written consent was obtained from all the patients and their complete and relevant demographic information including age, sex, ethnicity, residential history, education status, sexual behavior, drug abuse, and other risk factors was recorded. A medical history was obtained for each patient, and all patients received a full clinical examination. The diagnosis of the viral opportunistic infections was based exclusively on well defined clinical symptoms and the determination of specific antibodies in serum by 
ELISA. Data representing the patient groups in various risk factors as described in Table 1.

This study has been approved by appropriate human subject's research review board, by the Institutional Ethical Committee of ICMR Virus Unit, Kolkata, India.

\section{Laboratory examination and diagnosis of viral Ols}

The viral OIs were primarily diagnosed by the common clinical manifestations. For the diagnosis of CMV, the primary clinical symptoms were pneumonia, retinitis (an infection of the eyes), blindness and gastrointestinal disease The common clinical features of CMV disease is retinitis (which usually presents as painless, gradual loss of vision, floaters) followed by oesophagitis (presents as dysphagia - difficulty in swallowing or Odynophagia painful swallowing), colitis (presents as pain abdomen, bloody diarrhea, fever), pneumonitis (cough, breathlessness), encephalitis (altered mental status, convulsion, headache), radiculoneuropathy (weakness/paralysis of lower limbs, pain lower back, urinary retention) etc. Primary symptoms of HSV included persistent vesicular and ulcerative lesions of the oral and anogenital areas, often with extensive or deep ulcerations and blisters on or around the genitals or rectum. The blisters left tender ulcers (sores) that took two to four weeks to heal the first time they occurred. Other symptoms included tender tonsils covered with a whitish substance that made swallowing difficult or blisters present in the mouth. Primary diagnosis of EBV was based on the clinical symptoms of fever, sore throat and swollen lymph glands. The com-

Table 1: The HIV-seropositive patient groups in various risk factors

\begin{tabular}{lll}
\hline Risk Behavior & Male & Female \\
\hline Blood transfusion & 13 & 6 \\
\hline IVD abuse & 25 & 3 \\
\hline Heterosexual & 82 & 39 \\
\hline Homophiles & 20 & 12 \\
\hline Occupation & & \\
\hline Unemployed & 12 & 46 \\
\hline Government Service & 13 & - \\
\hline Non Government Service & 115 & 14 \\
\hline Deaths & 3 & 2 \\
\hline
\end{tabular}

monest clinical presentation of EBV disease in HIV positives is Oral hairy Leukoplakia (OHL). VZV was primarily diagnosed based on the clinical manifestations of severe headaches, backache, general malaise and fever accompanied by the typical exanthem (rash) of chickenpox. Other symptoms of VZV included painful oral lesions, vesicular rash, facial numbness and loss of hearing/ear pain. All the clinical manifestations were confirmed by ELISA test done in triplicates. The following diagnostic test kits were used for the assay of the opportunistic viruses:

\section{Anti- CMV}

Serum anti-CMV was determined by a commercially available test kit, CMV IgM, IgG ELISA Test kit supplied by EQUIPAR was used to detect antibodies against the CMV-IE1 and CMV-pp65mII.

Anti - EBV 1

Serum anti-EBV was determined by a commercially available test kit, EBV IgG, IgM ELISA Test kit supplied by Virotech/Germany was used to detect antibodies against the affinity-purified gp125 + p18 Peptide.

\section{Anti- HSV 2}

Serum anti- HSVwas determined by a commercially available test kit, HSV type1 IgM ELISA Test kit supplied by EQUIPAR was used to detect antibodies against the affinity-chromatographically purified recombinant antigen HSV-2.

\section{Anti - VZV}

Serum anti-VZV was determined by a commercially available test kit, VZV IgM, IgG, IgA ELISA Test kit supplied by Virotech/Germany was used to detect antibodies against the Ellen Strain antigen (ATCC).

\section{Evaluation of whole blood CD4+ Lymphocyte count}

The CD4+ count of the HIV seropositive patients $(\mathrm{n}=$ 200) was done at the discretion of the treating physicians. The CD4+ T cell percentages and the CD4+ counts were estimated by FACS Calibur flow cytometer (Becton Dickinson, San Jose, Calif., USA). Dual color immunophenotyping was performed using standard whole blood methodology.

\section{Statistical analysis}

The data was analyzed by the use of MINITAB Statistical software version 13.1. A regression model was fitted by using the data to analyze the effect of co-variates (i.e. age, sex, mode of infection, $\mathrm{CD} 4+$ ) on different response variable (i.e. different opportunistic infection). The Chi Square test of independence was used for statistical analysis and the Null hypothesis $\left(\mathrm{H}_{0}\right.$ hypothesis) has also been tested. A $P$ - value of $>0.05$ was regarded as statistically significant. The mean, median, mode and standard deviation has also been done by using the same software. 95\% Class Intervals and Kramer's V value, a measure of the 
strength of association among the levels of the row and column variables were calculated according to conventional methods. The purpose of the regression model and Chi Square test is to test the effect of different covariates on different response variables. Using the P-value method, one can conclude whether a given covariate has an effect on the response variable. From our data analysis, it is clear that age, sex, mode of transmission and CD4+ count (co-variates) have effects on the OIs (response variables) of our study subjects.

\section{Results}

Of the 200 HIV/AIDS patients studied, the samples positive for CMV, HSV, VZV, and EBV are 98 (49\%), 94 (47\%) $52(26 \%)$, and $65(32.5 \%)$ respectively. The incidence of CMV was higher among males than females 59/39. HSV was also found to be more predominant in the males 63/ 31. The incidence of VZV and EBV was also found to be dominant in the male population, the dominancy being $46 / 19$ and $31 / 21$ respectively.

Age related prevalence of opportunistic viral antibodies in the serum of $200 \mathrm{HIV}$ infected patient cohorts was assessed and results showed that individuals in the age group of 21- 40 years had the highest incidence of viral opportunistic infections as evident from Table. 2. The Figure 1 shows the respective opportunistic viral serum antibody incidence in the three age groups. The antibody OD with mean 0.275 , CI $(-0.34715,0.897152)$; mean 0.237 , CI $(-0.373,0.846336)$; mean 0.183 , CI $(-0.2251$,

Table 2: The different opportunistic viruses which infects HIV/AIDS patients of different age groups

\begin{tabular}{|c|c|c|c|c|}
\hline \multirow[b]{2}{*}{$\begin{array}{l}\text { Opportunistic } \\
\text { Viruses }\end{array}$} & \multirow[b]{2}{*}{ Sex } & \multicolumn{3}{|c|}{ Age Groups (in years) } \\
\hline & & $\leq \mathbf{2 0}$ & $21-40$ & $41-60$ \\
\hline \multirow[t]{2}{*}{ CMV } & Male & 9 & 37 & 13 \\
\hline & Female & 5 & 26 & 8 \\
\hline \multirow[t]{2}{*}{ EBV } & Male & - & 22 & 9 \\
\hline & Female & 2 & 15 & 4 \\
\hline \multirow[t]{2}{*}{ HSV } & Male & 9 & 43 & 11 \\
\hline & Female & 4 & 19 & 8 \\
\hline \multirow[t]{2}{*}{ VZV } & Male & 9 & 24 & 13 \\
\hline & Female & 2 & 10 & 7 \\
\hline
\end{tabular}

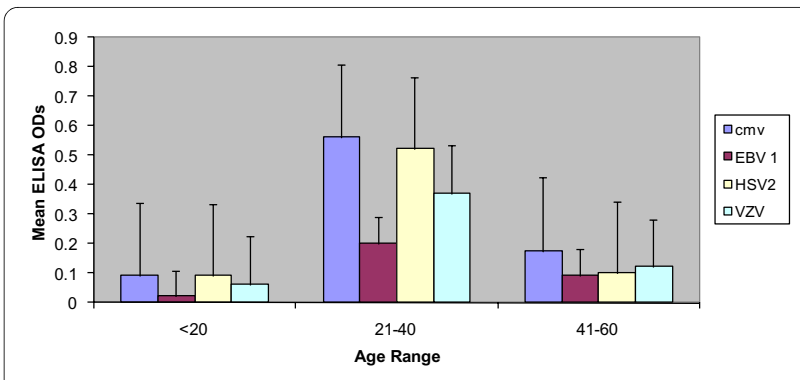

Figure 1 Opportunistic viruses and CD4+ count in our patient cohorts. The range of $\mathrm{CD} 4+$ counts $/ \mu \mathrm{L}$ of blood are shown in index. The number of samples positive against the respective Opportunistic viruses are shown in bars corresponding to the CD4+ counts in the blood.

0.591771) mean 0.103, CI (-0.2192, 0.328658) for CMV, HSV, VZV and EBV respectively.

Assessment of the risk factors associated with HIV transmission showed opportunistic viral incidence of HSV, CMV, VZV and EBV in Table. 3. HSV infection is found to be dominating in the heterosexual individuals among the study group. There are no significant variations among the homophiles, the drug users and the blood transfusion patients.

The incidence of the different viral OIs was also assessed with respect to the CD4+ cell count/ $\mu \mathrm{l}$ of blood and patients with mean CD4+ cell count of 51-100 showed the highest prevalence of opportunistic viral antibodies. This was followed by the group with $\mathrm{CD} 4+$ count of 101-150, 51-100, 151-200 and >200 (data not shown).

\section{Discussion}

Since the start of the epidemic, issues related to HIV/ AIDS have had a high profile in industrialized countries. However, the burden of the disease continues to fall most heavily, and often less visibly in developing countries [23]. Viral opportunistic infections and HIV/AIDS having become so intertwined have constituted a major public health problem in the country. The opportunistic infections, therefore, play a major role in clinical presentations and remain one of the most frequent causes of death in these patients. However in spite of this, very little information on viral opportunistic infections and HIV coinfection in India is available. A few reports documented were only on HBV-HIV co-infection [24,25]. Viral opportunistic infections have not been given their desired attention in the Indian health care delivery system, largely due to the dearth of information on the co-infection of HIV positive population with viral OIs. Our study was therefore, designed to assess the incidence of HSV, EBV, $\mathrm{CMV}$, and VZV infections among HIV patients in Eastern India so as to provide a baseline data on the dynamics of viral opportunistic infections in the immunocompromised population of Eastern India. 
Table 3: Association of HIV transmission Risk factors with the various Opportunistic Viruses of the patients blood samples

\begin{tabular}{|c|c|c|c|c|c|c|c|c|}
\hline \multirow[b]{3}{*}{ Opportunistic Viruses } & \multicolumn{8}{|c|}{ Risk Factors of HIV transmission } \\
\hline & \multicolumn{2}{|c|}{ Heterosexual } & \multicolumn{2}{|c|}{ Homophile } & \multicolumn{2}{|l|}{ IDU } & \multicolumn{2}{|c|}{ Blood transfusion } \\
\hline & Male & Female & Male & Female & Male & Female & Male & Female \\
\hline CMV & 27 & 19 & 13 & 8 & 13 & 2 & 9 & 3 \\
\hline EBV & 23 & 13 & 5 & 2 & 7 & - & 2 & - \\
\hline HSV & 43 & 12 & 11 & 6 & 9 & 3 & 7 & 3 \\
\hline VZV & 19 & 9 & 13 & 5 & 11 & - & 6 & 2 \\
\hline
\end{tabular}

Infection by cytomegalovirus (CMV) is the major cause of morbidity and mortality in individuals with depressed cell mediated immunity of congenital origin, iatrogenic origin and that associated with acquired immunodeficiency syndrome (AIDS). The clinical diagnosis of AIDS with CMV infection can be difficult in the absence of CMV retinitis, polyradiculopathy and the classical CMV syndrome [26,27]. The diagnosis poses difficulties because a 2-3 week period is mandatory for virus isolation. While IgM antibodies as detected by ELISA correlate poorly with the clinical status of CMV infection and facilities for culture are usually not available in most centers [28]. There are a few reports available of CMV infection in Indian patients with HIV/AIDS, which are based primarily on clinical or autopsy evaluation $[25,29,30]$. We found CMV as the most incidental co infection in HIV/ AIDS patient with the overall incidence of $49 \%$.

Human immunodeficiency virus (HIV) infection is associated with an increased risk for human herpesviruses (HHVs) and their related diseases. The incidence of HSV in human immunodeficiency virus (HIV)-seropositive patients has not been focused, with reports generally focusing on individual infection [31]. In this report, the serum prevalence of HSV is found to be higher in HIVseropositive patients; the overall incidence is around $47 \%$.

VZV infection, the overall incidence being $32.5 \%$ is the third most incidental coinfection in HIV seropositive patients. VZV is one of the common aetiological agents of viral retinitis. Neurological complications of the reactivation of VZV occur most frequently in elderly persons and immunocompromised patients [32]. Gray et al. reported VZV infection of the CNS in more than $4 \%$ of patients with AIDS examined at autopsy. In AIDS patients, VZV tends to reactivate from multiple dorsal root ganglia levels, and the disease is often disseminated.
EBV is the least prevalent among the four HHVs studied in our work which is $26 \%$ of the total. EBV has been identified as a co-factor in the pathogenesis of a significant proportion of HIV related lymphoproliferative disorders and in oral hairy leukoplakia [33]. However, only limited information exists on the status of EBV in the course of HIV infection and the extent of its interaction with HIV. There is also growing interest in the biological properties and pathogenic potential of the different EBV subtypes, EBV-1 and EBV-2. Serological findings and studies in saliva and blood have indicated a high incidence of EBV-2 infection in the course of HIV disease, but there is limited information regarding its significance [34-37].

The analysis of the association of immunological status and the presence of viral OIs revealed that the CD4 count was significantly associated with the presence of viral OIs. An increasing CD4 count significantly protected patients from expressing HHVs in our patient cohorts as indicated by the correlation as in Figure 2. It has been detected clinically that more frequently virus infections are associated with the compromised immunity in HIVinfected patients [38-41]. We found that, HIV-infected patients with CD4+ cell counts of around 200 cells $/ \mathrm{mm} 3$ are less likely to be infected with any virus examined here suggesting that a higherCD4+ cell count does play a role in immunity against virus infection. This clinical outcome is consistent with our finding of significantly lower CD4 cell count in HIV patients with viral OIs, indicating that the diagnosis of viral opportunistic infections can indeed be correlated with the clinical manifestation and thus is helpful in predicting disease progression. Figure 3 clearly shows that the patient group with CD4+ counts between 51 and 100 cells/ $\mu \mathrm{l}$ is most susceptible to viral OI in HIV/AIDS patient. The groups with CD4+ count less 


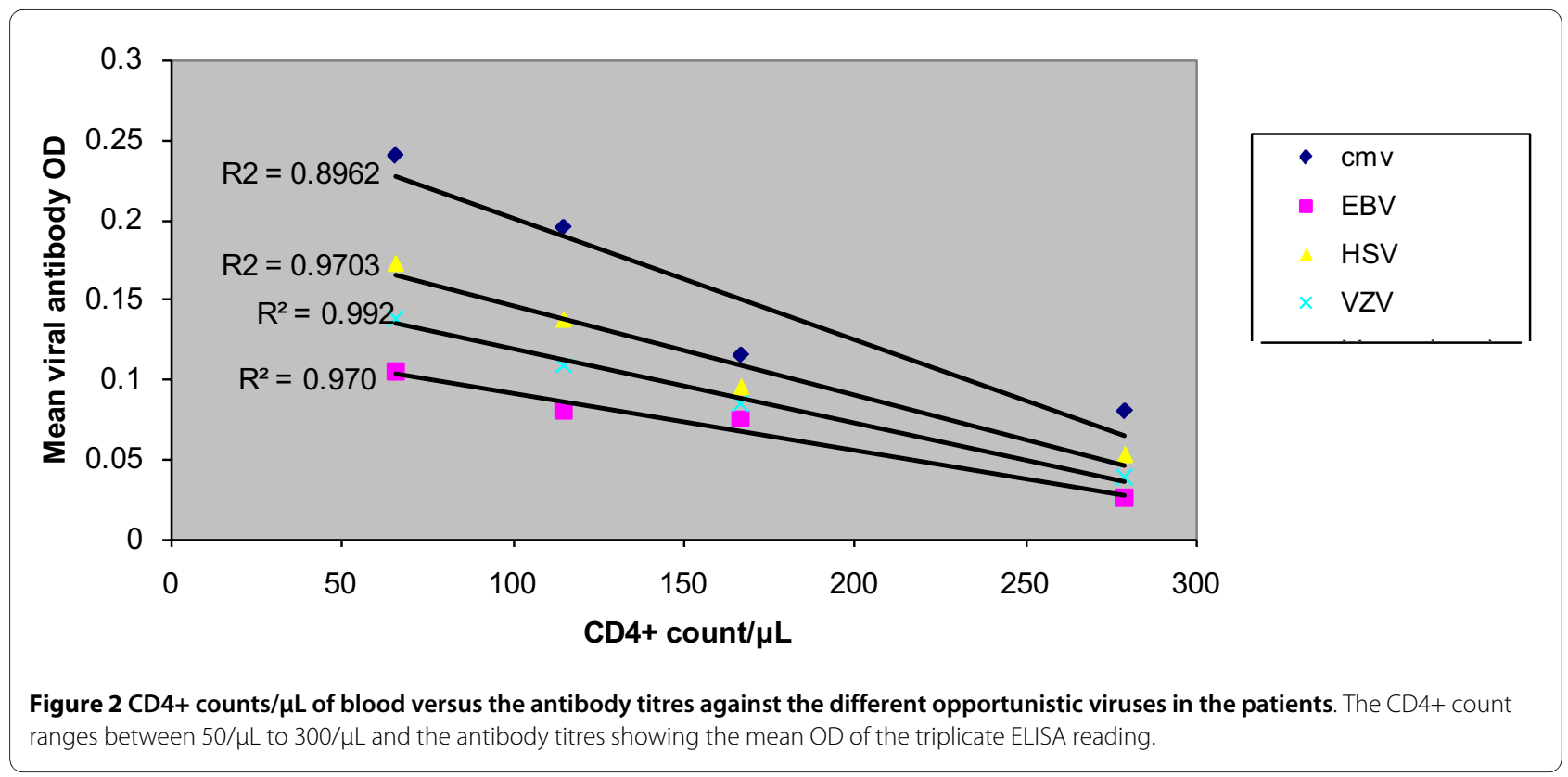

than 50 cells/ $\mu$ l are showing least opportunistic viruses which could be due to the advanced HAART treatment.

This study is aimed at providing baseline data on viral opportunistic infections in HIV seropositive population as part of the preliminary investigation on the dynamics of viral opportunistic infections in immunocompromised population of India. One of the major problems is the lack of specific investigations that can provide rapid and reliable confirmation of a clinical diagnosis. A high level of alertness is needed at both clinical and laboratory level and routine surveillance studies need to be undertaken. Institutions in India and other developing countries need to be equipped to face the emerging challenge, in the form of updating the present knowledge, by way of education and training of the personnel, acquisition of skills of improved procedures, and their implementation in appropriate settings with adequate administrative support. Further investigations have to be undertaken with matched control samples as case control analysis with

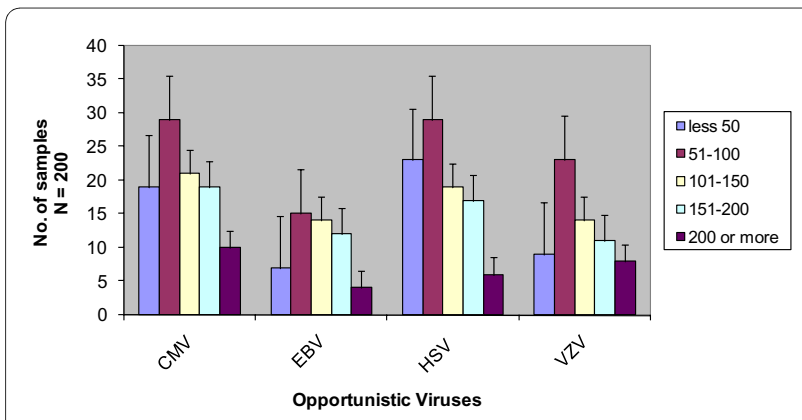

Figure 3 Antibody prevalence of the corresponding viruses in different age groups of our patients samples. respect to all HHV infection in HIV seropositive individuals in Indian perspective.

\section{Competing interests}

The authors declare that they have no competing interests.

\section{Authors' contributions}

CD and SB have equal contribution to the work. NC conceived and designed the study. RNS, SS, DB, SKG and UD supplied the samples and did HIV testing. $N C, C D, S B$ and $A M$ carried out the laboratory investigations. CD, SB and NC analyzed and interpreted the data and drafted the manuscript. Dw Bh did the statistical analysis. SC monitored the total project. NC reviewed the manuscript critically for medical and intellectual content. All authors read and approved the final manuscript.

\section{Acknowledgements}

The authors thank Mr. Probal Kanti Ray and Mr Tapan Chakrabarti for their laboratory help. This work was supported by intramural funds received from Indian Council of Medical Research, Government of India.

\section{Author Details}

'Virology Department, ICMR Virus Unit, ID \& BG Hospital, GB4, 57 Dr. SC Banerjee Road Beliaghata, Kolkata-700 010, India, 2Microbiology Division, National Institute of Cholera and Enteric Diseases P33 CIT Scheme-XM, Kolkata700 010, India, ${ }^{3}$ Department of Medicine, Calcutta Medical College and Hospital, 88 College Street, Kolkata-700 073, India, ${ }^{4}$ Department of Medicine, APEX Clinics, Calcutta Medical College and Hospital, 88 College Street, Kolkata 700 073, India and 5Department of Tropical Medicine, School of Tropical Medicine, 108 C.R Avenue, Kolkata- 700 073, India

Received: 28 January 2010 Accepted: 6 July 2010 Published: 6 July 2010

\section{References}

1. Quinn TC: Global burden of the HIV pandemic. Lancet 1996, 348:99-105.

2. Ran K, Hemalatha R: Oral lesions in HIV infection in developing countries: an overview. Advances in Dental Research 2006, 19:63.

3. Solomon S, Solomon S, Ganesh A: AIDS in India. British Medical Journal 2006, 82:545.

4. Brooks JT, Kaplan JE, Holmes KK, Benson C, Pau A, Masur H: HIVAssociated Opportunistic Infections-Going, Going, But Not Gone: The Continued Need for Prevention and Treatment Guidelines. Clinical Infectious Diseases 2009, 48(5):609-611. 
5. Piscitelli SC, Gallicano KD: Interactions among drugs for HIV and opportunistic infections. The New England Journal of Medicine 2001, 344(13):984.

6. Gershon AA: Varicella-zoster virus infections. Pediatrics in Review 2008 29(1):5

7. Weaver BA: Herpes Zoster Overview: Natural History and Incidence. JAOA: Journal of the American Osteopathic Association 2009, $109(6$ Supplement 2):S2.

8. Jallow S, Alabi A, Sarge-njie R, Peterson K, Whittle H, Corrah T, Jaye A Cotton M, Vanham G, Mcconkey SJ: Virological response to Highly Active Antiretroviral Therapy (HAART) in HIV-2 and HIV-1/HIV-2 Dually Infected Patients in The Gambia and the Emergence of Drug Resistant variants. Journal of Clinical Microbiology 2009. doi:10.1128/JCM.01654-08.

9. Pantanowitz L, Schlecht HP, Dezube BJ: The growing problem of nonAIDS-defining malignancies in HIV. Current Opinion in Oncology 2006, 18(5):469.

10. Mitsuyasu R: Malignancies in HIV: a growing problem. Current Opinion in Oncology 2007, 19(5):444.

11. Roberts S: Herpes simplex virus: incidence of neonatal herpes simplex virus, maternal screening, management during pregnancy, and HIV. Current Opinion in Obstetrics and Gynecology 2009, 21(2):124.

12. Sarna J, Sharma A, Naik E, Toney J, Msrfatia Y: Protean manifestations of herpes infection in AIDS cases. Indian Journal of Sexually Transmitted Diseases and AIDS 2009, 29(1):26.

13. Perez Cachaferio S, Del Amo J, Iribarren JA, Salavert Lleti M, Gutierrez F, Moreno A, Labarga P, Pineda JA, Vidal F, Berenguer J: Decrease in serial prevalence of coinfection with hepatitis $C$ virus among HIV-infected patients in Spain, 1997-2006. Clinical Infectious Diseases 2009, 48(10):1467-1470.

14. Bani-Sadr F, Lapidus N, Bedossa P, De Boever CM, Perronne C, Halfon P, Pol $S$, Carrat F, Cacoub P: Progression of fibrosis in HIV and hepatitis $C$ viruscoinfected patients treated with interferon plus ribavirin-based therapy: analysis of risk factors. Clinical Infectious Diseases 2008 , 46(5):768-774

15. Kaplan JE, Hu DJ, Holmes KK, Jaffe HW, Masur H, De Cock KM: Preventing opportunistic infections in human immunodeficiency virus-infected persons: implications for the developing world. American Journal of Tropical Medicine and Hygine 1996, 55:1-11.

16. Lucas, Sebastian B, Anatole Hounnou, Christopher Peacock, Anne Beaumel, Gaston Djomand, Jean-Marie N'Gbichi, Kouadio Yeboue, Michel Hondé, Mohenou Diomande, Christian Giordano, Ronan Doorly, Kari Brattegaard, Luc Kestens, Ronald Smithwick, Auguste Kadio, Niamkey Ezani, Achi Yapi, De Cock, Kevin M: The mortality and pathology of HIV infection in a West African city. AIDS 1993, 7:1569-1579.

17. Singh A, Bairy I, Shivananda PG: Spectrum of opportunistic infections in AIDS patients. Indian journal of Medical Sciences 2003, 57(1):16-21.

18. Khatter S: Mycobacterial infections in patients seropositive for human immunodeficiency virus. All India Institute of Medical Sciences, New Delhi; 1999.

19. Shailaja W, Pai LA, Mathur DR, Lakshmi V: Prevalence of bacterial and fungal agents causing lower respiratory tract infection in patients with human immunodeficiency virus infection. Indian Journal of Medical Microbiology 2004, 22:28-33.

20. Banerjee U: Progress in diagnosis of opportunistic infections in HIV/ AIDS. Indian Journal of Medical Research 2005, 121:395-406.

21. Miller CS, Berger JR, Mootoor Y, Avdiushko SA, Zhu H, Kryscio RJ: High prevalence of multiple human herpesviruses in saliva from human immunodeficiency virus-infected persons in the era of highly active antiretroviral therapy. Journal of clinical Microbiology 2006, 44(7):2409.

22. Sachithanandham J, Ramamurthy M, Kannangai R, Daniel H, Abraham O, Rupali P, Pulimood S, Abraham A, Sridharan G: Detection of opportunistic DNA viral infections by multiplex PCR among HIV infected individuals receiving care at a tertiary care hospital in South India. Indian Journal of Medical Microbiology 2009, 27(3):210.

23. Grant AD, De Cock KM: The growing challenge of HIV/AIDS in developing countries. BrMed Bull 1998, 54:369-381. 30. Halim NKD, Offor E, Ajayi Ol: Epidemiologic study of the seroprevalence of hepatitis-B surface antigen (HBsAg) and HIV-1 in blood donors. Nigerian Journal of Clinical Practice 1992, 2: 42-45.

24. Risbud A, Mehendale S, Basu S, Kulkarni S, Walimbe A, Arankalle V, Gangakhedkar R, Divekar A, Gadkari D, Paranjape R: Prevalence and incidence of hepatitis B virus infection in STD clinic attendees in Pune, India. British Medical Journal 2002, 78(3):169.

25. Lanjewar D, Anand B, Genta R, Maheshwari M, Ansari M, Hira S, Dupont H: Major differences in the spectrum of gastrointestinal infections associated with AIDS in India versus the west: an autopsy study. Clinical Infectious Diseases 1996, 23(3):482-485.

26. Eidelberg D, Sotrel A, Vogel H, Walker P, Kleefield J, Crumpacker CS: Progressive polyradiculopathy in acquired immunedeficiency syndrome. Neurology 1986, 36:912-6.

27. Wiley CA, Nelson JA: Role of human immunodeficiency virus and cytomegalovirus in AIDS encephalitis. American Journal of Pathology 1988, 133:73-81

28. Lazzarotto T, Dal Monte P, Boccuni MC, Ripalti A, Landini MP: Lack of correlation between virus detection and serologic tests for diagnosis of active cytomegalo virus infection in patients with AIDS. Journal of Clinical Microbiology 1992, 30:1027-9.

29. Santosh Vani T, Yasha C, Panda KM, Das S, Satishchandra P, Gourie-Devi M, Ravi V, Desai A, Khanna N, Chandramuki A, Swamy HS, Nagaraja D, Kolluri V, Sastry R, Shankar SK: Pathology of AIDS--Study from a Neuropsychiatric Centre from South India. Annual Indian Academical Neurology 1998, 1:71-82.

30. Lanjewar DN, Shetty CR, Catdare G: Profile of AIDS pathology in India. An autopsy study. In Recent advance in pathology New Delhi: Jaypee Brothers Medical Publishers; 1988:183-9.

31. Becker TM, Lee F, Daling JR, Nahmias AJ: Seroprevalence of and risk factors for antibodies to herpes simplex viruses, hepatitis $B$, and hepatitis $C$ among southwestern Hispanic and non-Hispanic white women. Sexually Transmitted Diseases 1996, 23(2):138.

32. Nebuloni M, Vago L, Boldorini R, Bonetto S, Costanzi G: VZV fulminant necrotizing encephalitis with concomitant EBV-related lymphoma and CMV ventriculitis: report of an AIDS case. Journal of Neurovirology 1998, 4(4):457-460.

33. Gustafsson A, Levitsky V, Zou JZ, Frisan T, Dalianis T, Ljungman P, Ringden O, Winiarski J, Ernberg I, Masucci MG: Epstein-Barr virus (EBV) load in bone marrow transplant recipients at risk to develop posttransplant lymphoproliferative disease: prophylactic infusion of EBV-specific cytotoxic T cells. Blood 2000, 95(3):807.

34. Mcclain $\mathrm{KL}$, Leach $\mathrm{CT}$, Jenson HB, Joshi W, Pollock BH, Parmley RT, Dicarlo FJ, Chadwick EG, Murphy SB: Association of Epstein-Barr virus with leiomyosarcomas in young people with AIDS. The New England Journal of Medicine 1995, 332(1):12.

35. Sixbey J, Shirley P, Chesney P, Buntin D, Resnick L: Detection of a second widespread strain of Epstein-Barr virus. Lancet 1989, ii:761-765.

36. Sculley T, Cros S, Borrow P, Cooper D: Prevalence of antibodies to Epstein-Barr virus nuclear antigen $2 \mathrm{~B}$ in persons infected with the human immunodeficiency virus. Journal of Infectious Disease 1988 158:186-192.

37. Kyaw MT, Hurren L, Evans L, Moss DJ, Cooper DA, Benson E, Esmore D, Sculley TB: Expression of B-type Epstein-Barr virus in HIV-infected patients and cardiac transplant recipients. AIDS Research and Human Retroviruses 1992, 8:1869-1874.

38. Smith DK, Neal JJ, Holmberg SD: Unexplained opportunistic infections and CD4 T-lymphocytopenia without HIV infection--an investigation of cases in the United States. The New England Journal of Medicine 328(6):373.

39. Orenstein JM, Fox C, Wahl SM: Macrophages as a source of HIV during opportunistic infections. Science 1997, 276(5320):1857.

40. Shieh B, Chang MJ, Ko WC, Chen EJ, Wu JC, Lee CF, Chang TT, Li C: Effects of Multiple Virus Coinfections on Disease Progression in HIV-Positive Patients. Intervirology 2003, 46:105-113.

41. Gray F, Belec L, Lescs M, Chretien F, Ciardi A, Hassine D, Flament-Saillour M, Truchis $P$, Clair B, Scaravilli F: Varicella-zoster virus infection of the central nervous system in the acquired immune deficiency syndrome. Brain 1994, 117(5):987.

doi: 10.1186/1743-422X-7-147

Cite this article as: Chakraborty et al., Incidence of multiple Herpesvirus infection in HIV seropositive patients, a big concern for Eastern Indian scenario Virology Journal 2010, 7:1471 